\title{
REVIEW
}

\section{Timing of light exposure affects mood and brain circuits}

\author{
TA Bedrosian ${ }^{1}$ and RJ Nelson ${ }^{2}$
}

Temporal organization of physiology is critical for human health. In the past, humans experienced predictable periods of daily light and dark driven by the solar day, which allowed for entrainment of intrinsic circadian rhythms to the environmental light-dark cycles. Since the adoption of electric light, however, pervasive exposure to nighttime lighting has blurred the boundaries of day and night, making it more difficult to synchronize biological processes. Many systems are under circadian control, including sleep-wake behavior, hormone secretion, cellular function and gene expression. Circadian disruption by nighttime light perturbs those processes and is associated with increasing incidence of certain cancers, metabolic dysfunction and mood disorders. This review focuses on the role of artificial light at night in mood regulation, including mechanisms through which aberrant light exposure affects the brain. Converging evidence suggests that circadian disruption alters the function of brain regions involved in emotion and mood regulation. This occurs through direct neural input from the clock or indirect effects, including altered neuroplasticity, neurotransmission and clock gene expression. Recently, the aberrant light exposure has been recognized for its health effects. This review summarizes the evidence linking aberrant light exposure to mood.

Translational Psychiatry (2017) 7, e1017; doi:10.1038/tp.2016.262; published online 31 January 2017

\section{INTRODUCTION}

Organisms on Earth are adapted to the 24-h solar day. Predictable daily cycles of light and dark allow for the synchronization of behavioral and biological processes to the external environment. For nonhuman animals, restricting activities to the appropriate temporal niche is crucial to fitness and survival. For humans, temporal organization of physiology is equally important for health and wellness. Over the past century, the boundaries of day and night have been obscured by the widespread adoption of electric light at night. Circadian disruption has become prevalent among wildlife and humans. A growing body of ecological research points to nighttime lighting near urban areas as a major disruption to wildlife migration, foraging activities, reproduction and immune function. ${ }^{3}$ For humans, health consequences of circadian disruption by light at night are becoming increasingly apparent. $^{2}$ Exposure to artificial light at night is linked to risk of breast cancer, metabolic disorders and psychiatric and behavioral disorders $^{3-7}$ (Figure 1). We focus below on human exposure to light at night and its consequences for circadian rhythms and mood.

Before the advent of electric lights about a century ago, humans were exposed to minimal light at night. A full moon on a clear night illuminated the environment $0.1-0.3$ lux, ${ }^{8}$ or up to 1.0 lux in the tropics. ${ }^{9}$ A candle placed a meter away casted only 1.0 lux of light. At the end of the Nineteenth century, with the invention of the electric light bulb, exposure to artificial light at night grew rapidly. For the first time, humans could effectively artificially extend the day. Night shift work was introduced soon after. As technology boomed, humans encountered even more sources of light at night, including television and computer screens, smartphones and tablet computers (Table 1). Today over $80 \%$ of the human population and $99 \%$ of those living in the United
States or Europe experience light pollution. ${ }^{10}$ Two-thirds of Europeans and nearly $80 \%$ of North Americans cannot see the Milky Way due to artificial night sky glow. ${ }^{10}$ Approximately 15$20 \%$ of the population is engaged in shift work and countless individuals are exposed to nightly light pollution from other sources. ${ }^{11}$ The light intensity on an average urban street is estimated at 5-15 lux and a typical living room at 100-300 lux. ${ }^{8}$ Electronic tablet computers emit $\sim 40$ lux, depending on the size of the screen. ${ }^{12}$ According to the National Sleep Foundation, $36 \%$ of parents and $34 \%$ of children leave an electronic device such as a television or computer on in their room while sleeping. ${ }^{13}$ In addition, $87 \%$ of women watch television in the hour before bedtime. ${ }^{14}$ This amount of nighttime light exposure is unprecedented in human history (Figure 2).

Exposure to light at night perturbs the circadian system because light is the major entraining cue used by the body to discriminate day and night. When exposure to light is mistimed or nearly constant, biological and behavioral rhythms can become desynchronized, leading to negative consequences for health. Mood disorders have long been associated with light and circadian rhythms. One example is seasonal affective disorder in which mood oscillates between dysthymia during the short day lengths of winter and euthymia during the long summer days. In fact, a striking number of mood disorders are either characterized by sleep and circadian rhythm disruption or precipitated by an irregular light cycle. Sleep disruption is a diagnostic criterion for major depression, bipolar disorder, post-traumatic stress disorder, generalized anxiety and other mood disorders. ${ }^{18}$ Circadian regulation permeates most systems believed to control mood, including limbic brain regions, monoamine neurotransmitters and the hypothalamic-pituitary-adrenal axis. Thus, it is reasonable that widespread exposure to light at night that disrupts circadian

\footnotetext{
${ }^{1}$ Laboratory of Genetics, Salk Institute for Biological Studies, La Jolla, CA, USA and ${ }^{2}$ Department of Neuroscience, Behavioral Neuroendocrinology Group, The Ohio State University Wexner Medical Center, Columbus, OH, USA. Correspondence: Dr TA Bedrosian, Laboratory of Genetics, Salk Institute for Biological Studies, 10010 N. Torrey Pines Road, La Jolla, CA 92037, USA.
} 


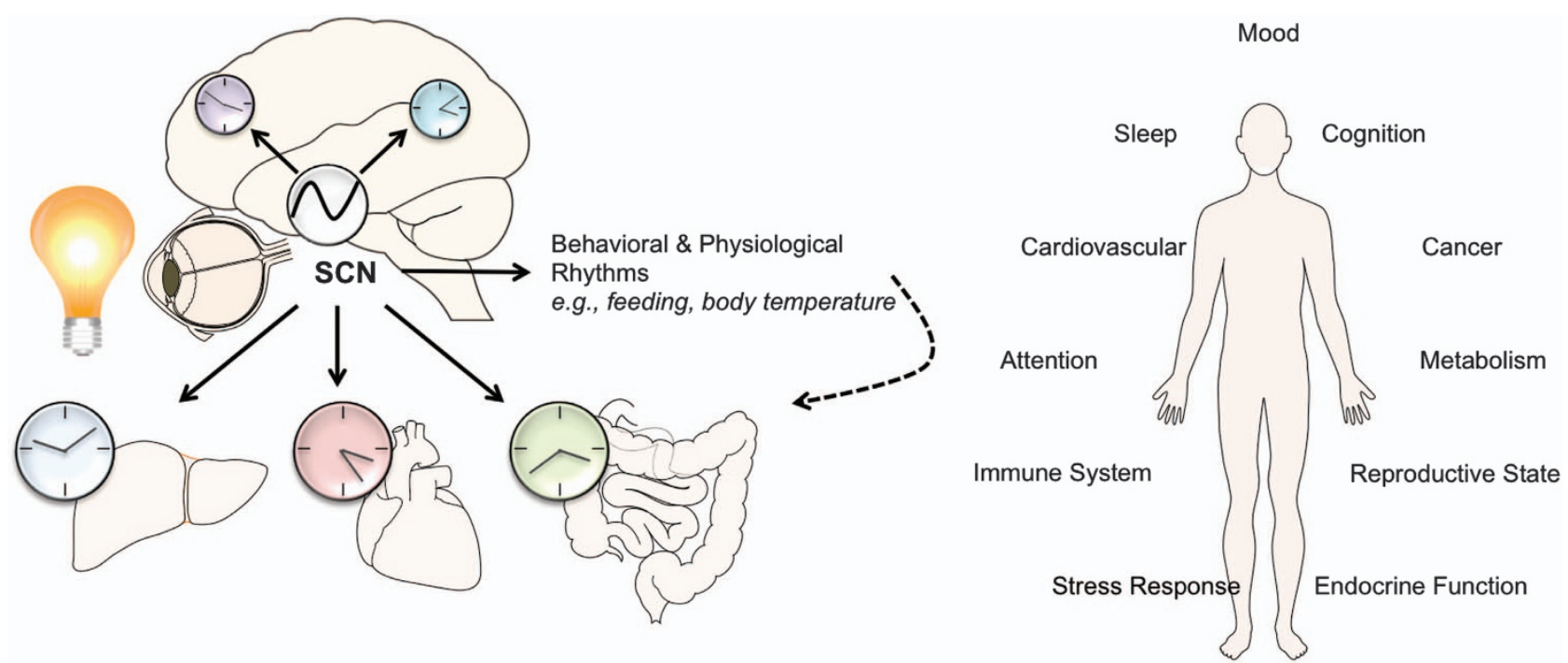

Figure 1. Health consequences of aberrant light exposure. Exposure to light at night or other circadian disruption can perturb synchronization of the central pacemaker in the suprachiasmatic nuclei (SCN) with peripheral clocks throughout the brain and body. Circadian disruption is associated with a number of negative health effects, including effects on mood, metabolism, cancer risk and the immune system.

\begin{tabular}{|c|c|c|c|}
\hline Overcast night sky & $0.00003-0.0001$ & At surface of Earth & Gaston et al. ${ }^{8}$ \\
\hline Full moon & $0.1-0.3$ & At surface of Earth & Gaston et al. ${ }^{8}$ \\
\hline Urban sky glow & 0.15 & At surface of Earth & Gaston et al. ${ }^{8}$ \\
\hline Residential side street & 5 & Unknown & Gaston et al. ${ }^{8}$ \\
\hline Smartphone & $>40$ blux $^{a}$ & $20 \mathrm{~cm}$ & Oh et al. ${ }^{15}$ \\
\hline ICU step-down unit & $1.3-47.3$ & Unknown & Fanfulla et al..$^{16}$ \\
\hline 24 Inch LED computer screen & $\sim 100$ & Unknown & van der Lely ${ }^{17}$ \\
\hline Intensive care unit (ICU) & 190.5 & Unknown & Meyer et al., ${ }^{119}$ \\
\hline Most homes & $100-300$ & Unknown & Gaston et $a l^{8}$ \\
\hline
\end{tabular}

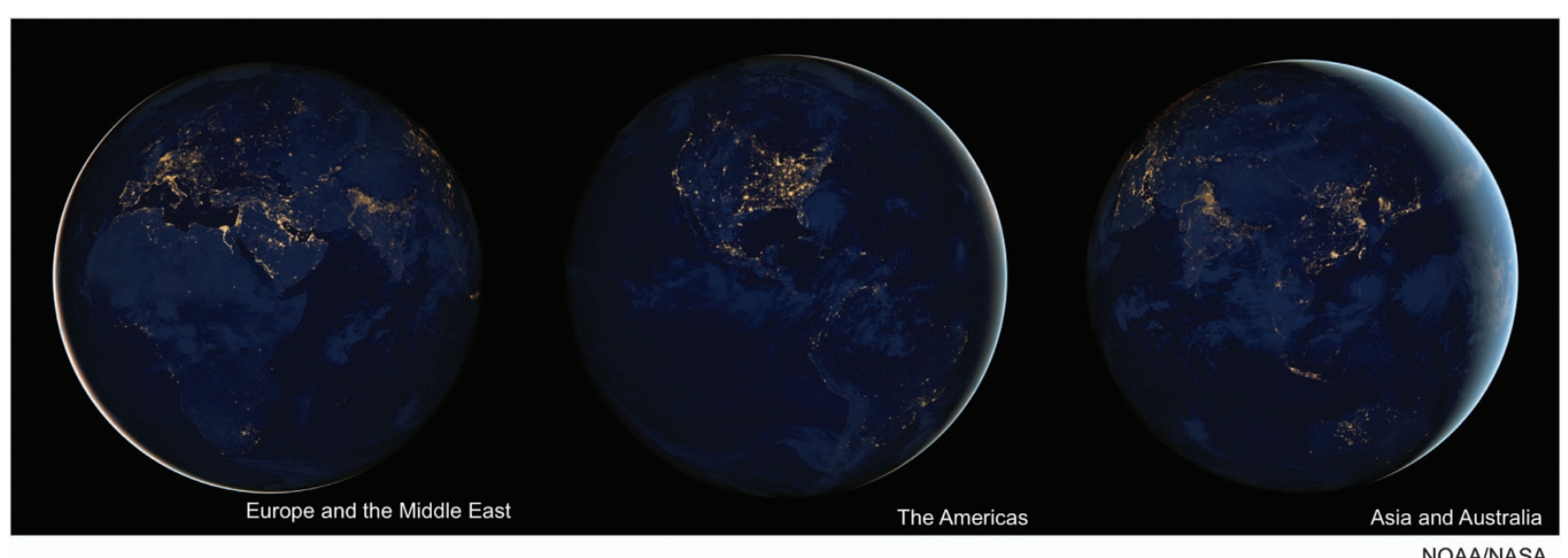

Figure 2. Satellite images of Earth at night. Images acquired by the Suomi National Polar-orbiting Partnership satellite in 2012 demonstrating urban light pollution (http://earthobservatory.nasa.gov/). 


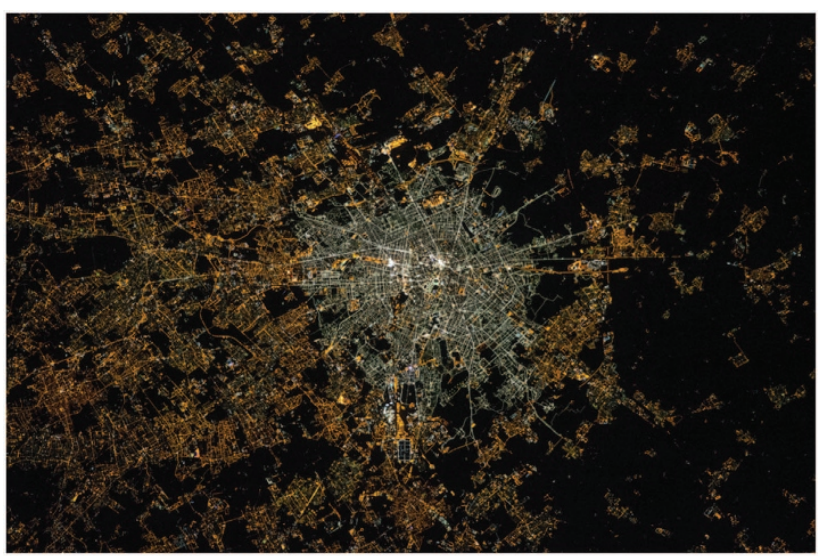

Samantha Cristoforetti/NASA/ESA

Figure 3. Transition to blue-shifted LED bulbs. Image of Milan, Italy taken in 2015 from the International Space Station after the transition to LED bulbs in the city center. The amount of blue light, known to most strongly stimulate the circadian system, is much higher compared with the surrounding suburbs (http://www.iau. org/public/images/detail/iau1510a/). LED, light-emitting diode.

function may contribute to the prevalence of mood disorders. ${ }^{19}$ Major depression in particular represents a serious public health concern, as the incidence is increasing in modern societies. ${ }^{20-22}$ We will review the evidence to date supporting the hypothesis that nighttime light affects mood. To do so, we will begin with a brief overview of normal circadian function, followed by a discussion of mechanisms through which light may affect mood, and finally, present examples from human and rodent studies, directly demonstrating consequences of chronic nighttime light exposure on mood.

\section{LIGHT DETECTION AND CIRCADIAN FUNCTION}

In mammals, the retina detects light using specialized photoreceptor cells. The classical photoreceptors, rods and cones are primarily responsible for image-forming vision. The third class of photoreceptors, called intrinsically photosensitive retinal ganglion cells (ipRGCs), perform non-image-forming functions, including circadian phototransduction. ipRGCs represent a small fraction of the larger class of retinal ganglion cells, but their expression of the photopigment melanopsin makes them uniquely photosensitive. ${ }^{23}$ In the absence of rods and cones, ipRGCs are sufficient to entrain circadian responses to light ${ }^{24}$ and maintain normal photic melatonin suppression. ${ }^{25}$ On the other hand, mice lacking the melanopsin gene still entrain to light cycles, but only to a lesser degree. ${ }^{26}$ They also exhibit defects in phase-resetting in response to light pulses, highlighting the importance of melanopsin to circadian photoentrainment. ${ }^{27}$

The spectral characteristics of melanopsin responses are such that blue light $(\sim 480 \mathrm{~nm})$ most strongly stimulates ipRGCs, whereas red light $(>600 \mathrm{~nm})$ has minimal effect. ${ }^{28}$ Interestingly, daytime sunlight contains more blue wavelengths than sunset. As the sun gets closer to the horizon, short wavelengths are scattered in the atmosphere and longer, redder wavelengths more easily reach the surface of the Earth. The sensitivity spectrum of melanopsin may be an adaptation to the natural solar cycle, so that ipRGCs are tuned to discriminate daylight from evening, better entraining the circadian rhythm. Recently, some countries have mandated a switch from incandescent bulbs to compact fluorescent bulbs or light-emitting diodes (LEDs) to save energy (Figure 3). Depending on the color temperature, some compact fluorescents and LEDs produce a blue-shifted spectrum relative to incandescent bulbs, to which the human circadian system is most sensitive. ${ }^{29}$ It will be important to consider the biological effects of lighting spectrums in home and workplace design. When exposed to light in the activating spectrum, ipRGCs directly project to the body's circadian master clock, the suprachiasmatic nucleus (SCN) of the hypothalamus. In addition, they have other direct and indirect targets throughout the brain, including mood-related structures. ${ }^{30}$ As a primary function, light detected by ipRGCs sets the molecular clock in the SCN.

The molecular clock in the SCN is composed of a set of transcriptional-translational feedback loops that drive rhythmic 24-h expression of the core clock components. ${ }^{31}$ In the primary feedback loop, CLOCK and BMAL1 proteins form heterodimers that activate gene expression of Period (Per) and Cryptochrome (Cry). PER and CRY proteins then heterodimerize and translocate into the nucleus, where they repress their own transcription by acting on the CLOCK/BMAL1 complexes. In an interacting feedback loop, CLOCK/BMAL1 complexes activate expression of retinoic acid-related orphan nuclear receptors, Rev-erba and $R O R a$. Their protein products feedback to regulate Bmal1 by competitively binding retinoic acid-related orphan receptor response elements in the Bmal1 promoter. Reverse viral erythroblastosis oncogene products repress the transcription of Bmal1, whereas RORs activate it. These two loops form the basis of the molecular clock, but a complex network of interacting genes and post-translational modifications ensure that the process takes $\sim 24 \mathrm{~h}$ to complete. ${ }^{32}$ Again, this transcriptional-translational feedback loop is the basis of the intrinsic daily circadian rhythm.

In the absence of any environmental signals, the molecular clock will continue to produce $\sim 24-h$ rhythms. Ex vivo cultures of SCN neurons continue to express near 24-h rhythms for weeks after being removed from the body. ${ }^{33}$ Humans living in caves without any light or temperature cues will maintain circadian sleep-wake and body temperature rhythms, although they begin to free-run on a cycle slightly longer than $24 \mathrm{~h}^{34}$ Therefore, light serves as the major entraining cue to maintain perfect synchrony with the environment. Light detected at night phase shifts the cycle by rapidly inducing expression of Per 1 or Per2, depending on whether the light occurs in early or late night. ${ }^{35-37}$ Phase shifting can be useful for adapting to changing seasonal day lengths or a new time zone, but it can be detrimental when unwarranted. For example, using electronics at night can unintentionally phase shift the circadian rhythm, leaving it decoupled from the natural environmental light-dark cycle. ${ }^{38}$

The SCN functions as the central circadian pacemaker, although the intracellular clock mechanism is expressed in other brain regions and in peripheral tissues. Clocks throughout the body remain synchronized with one another by responding to signals from the SCN, either through direct neural inputs or indirect cues such as hormonal, behavioral and physiological rhythms. For example, rhythms in feeding and body temperature can help synchronize peripheral oscillators. ${ }^{39,40}$ Aberrant light exposure that disrupts these rhythms may drive downstream dysregulation of circadian rhythms in peripheral systems. Of note, time of day information reaching the pineal gland via the SCN potently regulates secretion of the hormone melatonin. Melatonin is a small indoleamine that is produced and secreted in a 24-h rhythm that peaks at night. Circulating melatonin aids in entrainment of clocks located in peripheral organs through a number of interactions with the molecular clock mechanism, including phase-resetting clock genes. ${ }^{41}$ Exposure to light at night, even at very low intensities, strongly inhibits melatonin secretion, which may disrupt overall synchrony of the central and peripheral clocks. ${ }^{42}$ In addition, the circadian system regulates glucocorticoid secretion from the adrenal glands such that concentrations tend to peak in the morning just before awakening and decrease throughout the day. ${ }^{43}$ Glucocorticoids are important in stress responses through their role in the hypothalamic-pituitaryadrenal axis, where they are involved in a negative feedback 

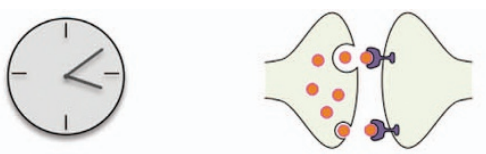

Sleep-Wake Cycle

Neurotransmission

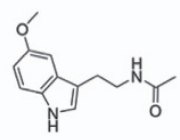

Melatonin Secretion
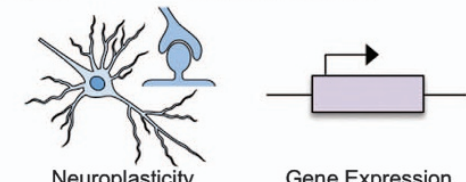

Gene Expression

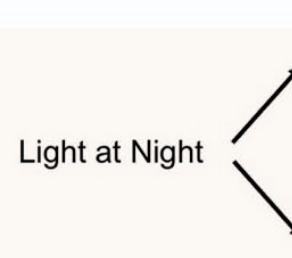

Indirect disruption of homeostatic processes involved in mood

\section{.}

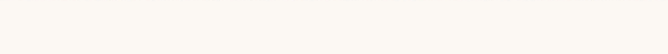

Direct ipRGC stimulation of brain regions involved in mood

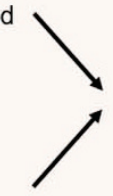

Depressed Mood
And deficits in learning \& memory, cognition, stress response

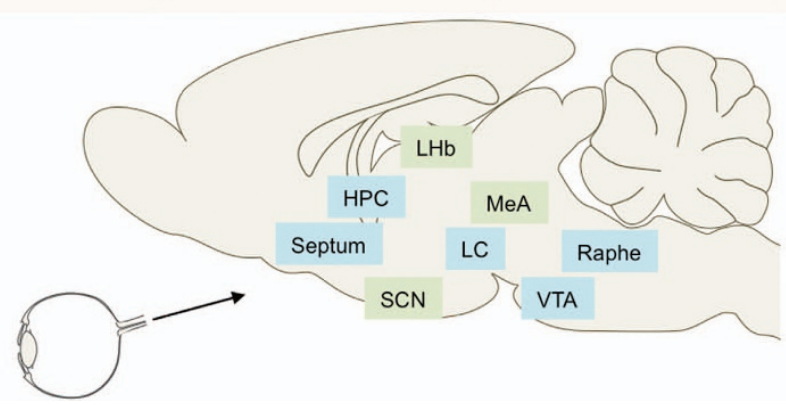

Figure 4. Mechanisms of depressed mood caused by exposure to light at night. Studies in rodent models have revealed several putative mechanisms through which exposure to artificial light at night disrupts mood. Nighttime light can indirectly affect mood by disrupting sleep, hormone secretion, neuroplasticity, neurotransmission or gene expression. In parallel, nighttime light can directly affect mood through aberrant signals transmitted from ipRGCs in the retina to brain regions involved in emotional regulation. In the panel, green brain regions represent primary ipRGC targets and blue regions represent secondary targets. HPC, hippocampus; ipRGC, intrinsically photosensitive retinal ganglion cells; LC, locus coeruleus; LHb, lateral habenula; MeA, medial amygdala; SCN, suprachiasmatic nucleus of the hypothalamus; VTA, ventral tegmental area.

loop to maintain homeostatic concentrations of stress hormones. Glucocorticoid dysregulation has been associated with a number of mood disorders; in particular, hypercortisolemia is detected in a subset of major depression patients. ${ }^{44}$ Light directly affects secretion of glucocorticoids in humans, suggesting mistimed light exposure interacts with the hypothalamic-pituitary-adrenal axis and stress responsivity. ${ }^{45}$

\section{ABERRANT LIGHT EXPOSURE AND THE BRAIN}

Much of the evidence for effects of aberrant light exposure on the brain has arisen from studying model organisms, including rodents. Many rodent species are nocturnal, unlike humans, meaning that exposure to light at night occurs during their active and awake phase. Indeed some effects of nighttime light are likely attributed to sleep disruption in humans, but studies using nocturnal species show that it is not the only cause. Studies in diurnal Nile grass rats have attempted to overcome this difference. Another important difference between humans and rodents is the production of pineal melatonin. Although both nocturnal and diurnal species produce melatonin during the dark phase, certain inbred laboratory strains of mice have no detectable pineal melatonin rhythm at all. Studies performed using $\mathrm{C} 57 \mathrm{bl} / 6$ mice (no detectable pineal melatonin) versus Siberian hamsters (robust pineal melatonin rhythm) have reported similar effects of light at night on affective responses. This demonstrates that melatonin suppression by nighttime light is not the only mechanism, but still may be an important contributor in humans and a potential point of intervention.
Accumulating evidence demonstrates both direct and indirect connections between artificial light at night and mood regulation. For one, aberrant light exposure can directly affect mood through ipRGC projections to brain regions involved in emotionality. ${ }^{46,47}$ Mice exposed to an alternating cycle of $3.5 \mathrm{~h}$ light and $3.5 \mathrm{~h}$ dark (termed T7), which does not significantly affect cycling clock gene expression or sleep, developed behavioral symptoms reminiscent of depression. ${ }^{47}$ Mice lacking the melanopsin gene were protected against such depressive responses, suggesting the behavioral changes occurred because ipRGCs project either directly or via the $\mathrm{SCN}$ to brain regions involved in mood..$^{30}$ In addition, there are several indirect pathways affected by light at night that may contribute to mood disturbances (Figure 4). A host of behavioral and brain changes have been implicated in mood disorders, including disruption of sleep, brain plasticity, neurotransmission, hormone secretion and gene expression. All of these processes are to some extent under circadian control and thus vulnerable to disruption by environmental perturbations of daily rhythms. This section discusses some of many possible mechanisms for the behavioral and emotional effects of artificial nighttime lighting.

\section{Sleep}

Sleep disturbance is an important factor contributing to the onset and maintenance of mood disorders. ${ }^{48}$ One of the most obvious potential effects of nighttime lighting is sleep disruption. During dark nights, melatonin concentrations rise to promote sleep onset and regulate circadian sleep phase. ${ }^{49-51}$ Exposure to light at night strongly suppresses melatonin, which interferes with sleep timing 
and sleep quality. Individuals who used an eReader (30-50 lux) during the $4 \mathrm{~h}$ before bedtime experienced increased latency to fall asleep and decreased morning alertness. The symptoms coincided with a significant suppression of melatonin. ${ }^{38}$ Similarly, individuals who slept with a night light of $\sim 40$ lux had shallower sleep and increased arousals, as well as markedly decreased brain oscillations during sleep. ${ }^{52}$ Brain oscillations during sleep have been linked to cognition; so it is possible that even relatively low levels of nighttime light could have detrimental effects on cognitive function through sleep disruption. ${ }^{53,54}$ Interestingly, indoor light pollution is not the only source of sleep disruption. Two large epidemiological studies reported that even light pollution outside the home was sufficient to disrupt sleep. In a study of more than 19000 individuals, those living in areas with more outdoor night lighting self-reported less quality and quantity of sleep, as well as more daytime sleepiness. ${ }^{55}$ In another cohort of almost 9000 individuals, symptoms of insomnia and snoring were associated with areas of high light pollution. ${ }^{56}$ Although mood was not investigated in these studies, sleep and emotional regulation are intimately linked; sleep disruption is one potential mechanism through which light at night is implicated in depressed mood. ${ }^{57}$ However, sleep is likely only one of several contributors because nocturnal mice develop depressive responses after exposure to light at night without experiencing any sleep disruption. ${ }^{58,59}$ The data seem consistent with light at night deranging circadian clocks, sleep being one of the 'hands' of the endogenous biological clocks.

\section{Rhythmic expression of clock genes}

Clock gene disruption is another core contributor to the effects of light at night. Exposure to light at night alters expression of clock genes and interacts with existing circadian gene variants that may predispose to mood disorders. Mice and hamsters exposed to dim light at night consistently show blunted amplitude of clock gene expression in the brain. ${ }^{60-62}$ Circadian genes appear to have critical roles in mood regulation, as mutations in a number of them have been linked to various behavioral impairments related to mood. For example, mice with a mutation of the Clock gene display a behavioral profile similar to mania in humans, including hyperactivity, reduced sleep and increased reward sensitivity. ${ }^{63}$ Genome-wide association studies identified polymorphisms in circadian genes that associated with psychiatric diseases, ${ }^{64-66}$ suggesting that abnormalities in clock gene function may be a cause rather than an effect of mood disorder pathology.

\section{Jet lag}

Phase shifts induced by jet lag represent a relevant model of desynchrony between intrinsic biological rhythms and external environmental rhythms. Typically, jet lag is associated with rapid phase shifting and light exposure out of phase with the biological rhythm. Vasopressin signaling in the SCN resists external perturbation and maintains a steady intrinsic rhythm, making it somewhat difficult to adjust to a new time zone. Mice lacking vasopressin receptors $\mathrm{V} 1 \mathrm{a}$ and $\mathrm{V} 1 \mathrm{~b}$ more easily phase shift their rhythms to re-entrain to a new light cycle, showing improved ability to cope with artificial jet lag. ${ }^{67}$ Experimental models of chronic jet lag have revealed profound effects on brain function and behavior. Hamsters subjected to 6-h phase advances every 3 days for 25 days developed learning and memory deficits that coincided with reduced hippocampal cell proliferation and neurogenesis. ${ }^{68}$ Phase advances induce a larger decrease in neurogenesis compared with phase delays, in agreement with the observation that phase advances are more disruptive to mouse clock gene expression than phase delays. ${ }^{69}$ In humans, flight attendants working transmeridian flights with short recovery time between shifts developed temporal lobe atrophy ( 3\% decrease in volume on average) and cognitive deficits ( $10 \%$ decrease in reaction time and correct response rate to a visual spatial task). ${ }^{70}$ Similarly, patients admitted for psychiatric emergencies who recently traveled across time zones were more likely to display symptoms of depression or mania compared with non-travelers. ${ }^{71}$ These findings implicate structural changes in the brain as one downstream effect of circadian rhythm disruption.

\section{Seasonal changes in day length}

Seasonal changes in day length are known to alter mood. At temperate latitudes, nearly $10 \%$ of the population experiences winter depression characteristic of seasonal affective disorder. ${ }^{72}$ Symptoms remit when day lengths become longer during the summer months. The symptoms of seasonal affective disorder are thought to relate to a phase shift in the pineal melatonin rhythm caused by lower levels of daylight. Bright light therapy in the morning suppresses melatonin secretion and re-entrains the rhythm, improving symptoms in some patients. ${ }^{73}$ At very high latitudes, individuals experience nearly constant daylight during certain times of the year. In some parts of Finland north of the Arctic Circle, the sun does not set for 60 days during the summer. At least one group has reported violent suicides increase dramatically during these periods. ${ }^{74,75}$ These observations indicate that appropriately timed light exposure is important for circadian function and mood. Either a lack or an excess of light can have significant effects on health and mood.

\section{Neuroplasticity}

Impaired neuroplasticity is a feature of major depression, such that patients display reduced hippocampal volume, ${ }^{76-78}$ lower levels of brain-derived neurotrophic factor (BDNF) $)^{79}$ and deficits in functional plasticity. ${ }^{80}$ Changes in adult neurogenesis or neuronal morphology have been observed in several animal models of depression. ${ }^{81}$ Circadian disruption is thought to induce structural changes in the brain, which could affect the functional connectivity of regions involved in mood regulation. Specifically, rodent studies have consistently found a relationship between the lighting environment and the rate of adult hippocampal neurogenesis. Adult mice housed in continuous light had reduced hippocampal neurogenesis and impairments in learning and memory in a water maze task. ${ }^{82}$ As mentioned above, hamsters subjected to chronic phase shifts, a paradigm mimicking jet lag in humans, displayed similar reductions in neurogenesis and learning and memory ability. ${ }^{68}$ Structural and functional complexity of neurons is similarly affected. Mice subjected to circadian disruption through a 20-h light/dark cycle exhibited a loss of dendritic length and complexity in neurons of the prelimbic prefrontal cortex, associated with anxiety and learning deficits. ${ }^{83}$ Rats housed in constant light had impaired performance in the Morris water maze and impaired ability to form long-term depression. ${ }^{84}$ These effects are consistent in both nocturnal and diurnal animals. In Nile grass rats, a diurnal model, dim light at night provoked similar depressive behaviors and reduced the length of dendrites on hippocampal CA1 and dentate gyrus granule neurons. ${ }^{85}$ Harnessing our knowledge of the spectral sensitivity of ipRGCs could reduce the effects of artificial light at night. Housing hamsters in dim light at night caused depressive responses and reduced the density of dendritic spines on hippocampal CA1 neurons in a wavelength-dependent manner, such that red light had a minimal effect compared with white or blue light. ${ }^{86,87}$

\section{Neurotransmission}

Monoamine (that is, serotonin (5-HT), dopamine (DA), norepinephrine) transmission is thought to be impaired in depressive disorders and it is the primary target of most current antidepressant medications. Several of these neurotransmitters and their 
receptors display circadian rhythms in concentration, release and expression. ${ }^{88-92}$ Monoamine oxidase A (Maoa) transcription is regulated by clock components such that a mutation in Per2 reduces MAOA activity. ${ }^{93}$ These findings imply that environmental circadian disruption that perturbs clock gene expression will also modulate neurotransmitter systems, suggesting that impaired neurotransmission is another potential mechanism of depressed mood caused by nighttime lighting. Indeed, exposure to light at night seems to alter neurotrophin and neurotransmitter systems. Mice exposed to 4 weeks of dim light at night displayed depressive symptoms and reduced Bdnf mRNA expression in the hippocampus compared with mice exposed to a typical light-dark cycle. ${ }^{59}$ Mice exposed to $4 \mathrm{~h}$ of light in the middle of an otherwise dark night also reduced Bdnf mRNA expression in the hippocampus and other brain regions involved in emotional regulation. ${ }^{94}$ Several neurotransmitter systems have been investigated for their relationship to environmental light. DA, glutamate and GABA concentrations oscillate in a circadian rhythm in the rat striatum and nucleus accumbens; the DA rhythm is responsive to light, whereas the others are less responsive. ${ }^{95}$ Furthermore, housing rats under continuous lighting abolishes late afternoon declines in DOPA within the median eminence, but melatonin injections restore the rhythm. ${ }^{96}$ DA is just one example of the connection between environmental lighting and neurotransmitter systems. Indeed the effect of light can be so profound that exposure to long versus short photoperiods causes hypothalamic interneurons to switch between DA and somatostatin expression in the rat brain. ${ }^{97}$ The specific regimen of light exposure seems to be important, however, because some artificial light cycles may not have the same effect as others. Exposure to an artificial light cycle consisting of $6 \mathrm{~h}$ light and $6 \mathrm{~h}$ dark reduced 5-HT levels and increased norepinephrine levels, while leaving DA levels unchanged. ${ }^{98}$

\section{ABERRANT LIGHT EXPOSURE AND MOOD}

Given the sensitivity of the molecular clock to the timing, intensity and spectra of illumination, artificial light at night can cause serious circadian and physiological disruption. Exposure to light at night is prevalent throughout life, beginning in early childhood and extending into old age. This chronic level of nighttime light exposure is unprecedented in human history. A growing body of research shows that one consequence of nighttime lighting is disrupted mood regulation and that humans are sensitive across the lifespan.

Childhood and adolescence are periods of likely exposure to light at night, as well as sensitive windows for brain development. Children commonly sleep with night lights and adolescents tend to stay up late at night using electronics. A 1999 survey found that only $10 \%$ of young people aged $2-16$ slept in complete darkness. $^{99}$ Exposure to light at night affects the circadian phenotype of these individuals. Adolescents living in dense, urban areas with high levels of outdoor illumination have stronger evening-oriented chronotypes than those living in darker, rural areas, as do adolescents with more evening use of electronic media. ${ }^{100}$ Compounding the tendency to stay up later, young people tend to be more sensitive to the melatonin-suppressing effects of light at night than adults. ${ }^{101}$ Research efforts should focus on determining the long-term effects of circadian disruption by light at night during early life, as studies in rodents suggest there are long-lasting consequences of exposure. Mice exposed to dim light at night during the first 3 weeks of life had increased anxiety as adults. ${ }^{102}$ Rats exposed to constant bright light in early life also displayed permanent changes in emotionality, but they were protected against developing depressive-like behaviors when exposed to constant light again as adults. ${ }^{103}$ Considering the widespread exposure to nighttime light in early life, these results should be pursued with additional research.
Among the adult population of developed societies, $15-20 \%$ of individuals are engaged in shift work that exposes them to light at night on a chronic or rotating basis. Epidemiological studies repeatedly link shift work to symptoms of depression. Workers exposed to shift work are more likely to suffer depressive episodes, with prolonged shift work of more than 20 years resulting in increased lifetime risk of major depression. ${ }^{104}$ Even a single night of shift work among student nurses elicited changes in mood. ${ }^{105}$ Multiple components involved in night shift work may affect mood, including exposure to light and sleep disruption. These components will need to be teased out in additional experiments, but there is evidence that appropriately timed bright light therapy can improve mood in shift workers. Restricting light exposure to the night and maintaining darkness during the day allowed workers to adapt to a reversed circadian cycle, which improved alertness and cognition. ${ }^{106}$ Unfortunately, maintaining a reversed circadian cycle is difficult under typical circumstances, as workers revert back to a standard cycle on weekends or off days, which disrupts their circadian function further. Likewise, exposure to just 30 min of bright light (>3000 lux) during the work shift improved the mood of night shift nurses, ${ }^{107}$ but this was likely a short-term effect that would not ameliorate symptoms of depression resulting from long-term night shifts. Interestingly, there are individual variations in sensitivity to light at night, just as there are individual variations in circadian chronotype, and these differences may be related to mood. Manic-depressive individuals awakened and exposed to an acute bout of light at night experienced more than twice the decrease in melatonin concentrations as individuals not diagnosed with bipolar disorder. ${ }^{108}$ Among non-shift working adults there are far less data available to assess the effects of chronic nighttime lighting on mood. As described earlier, virtually all individuals living in North America or Europe are exposed to nightly light pollution, but there is a lack of systematic research investigating the effects. In rodents, exposure to dim light at night (5 lux) each night for 34 weeks elicited depressive-like symptoms. ${ }^{59,85-87}$ In humans, the incidence of major depression has grown in parallel with the adoption of electric lights, but this is only correlation. Interestingly, the Amish population rejects electricity and has remarkably low incidence of depression. ${ }^{109}$ Epidemiological studies are warranted to assess this relationship.

Elderly individuals institutionalized in hospitals or nursing facilities are particularly vulnerable to exposure to artificial light at night because 24-h nursing activities and safety concerns require constant lighting. Circadian disruption is already a factor in the natural aging process, as the melatonin rhythm decreases in amplitude and sleep becomes more fragmented. ${ }^{110}$ In a cohort of 857 elderly individuals, exposure to light at night was associated with insomnia and poor sleep quality, ${ }^{111}$ which could be contributing factors to depressed mood. In another cohort of 516 elderly individuals, both intensity and duration of exposure to light at night were associated with depressive symptoms. Depressed individuals averaged more than 5 lux of light at night and more than $30 \mathrm{~min}$ of nightly exposure, compared with only 0.8 lux in the non-depressed group. Interestingly, depressive symptoms did not correlate with melatonin concentrations. ${ }^{112}$ If it is feasible for the particular case, then timing light exposure to a more appropriate circadian phase could be a strategy to reduce depression among the aged population. Among elderly patients with dementia, sleep consolidation and behavioral disorders were improved by morning light therapy, indicating light is powerful both as a disruptor or synchronizer depending on the timing. ${ }^{113}$ It is also becoming apparent that lack of exposure to bright light during the day can contribute to mood changes. In one study, women who had a window were exposed to higher light levels during the day and reported better sleep and lower depressive symptoms than women working in similar jobs, but without office windows. $^{114}$ 


\section{CONCLUSIONS AND CONSIDERATIONS}

The introduction of electric light was a pivotal moment in history, finally allowing humans greater flexibility in controlling the environment. It led to safer, wealthier, more productive societies. Unfortunately, the field of circadian biology lagged behind the widespread adoption of electric light. Only now are we learning about the effects of artificial light at night on the brain and body. In 2007, the World Health Organization designated shift work as a 'probable carcinogen' after findings from epidemiological and laboratory studies proved that light at night increases the risk of breast cancer. ${ }^{4,6,115,116}$ In 2016, the American Medical Association issued a report cautioning against blue-rich LED streetlights, citing the detrimental effects on human health. ${ }^{117}$ Most recently, a growing scientific consensus suggests that light at night negatively affects mood. This is important research because it deals with a ubiquitous phenomenon. As the human population expands, and developing countries further modernize their cities and industries, light pollution will grow to affect even more people. The list of biological systems affected by light at night is long, but additional research will tease out the critical systems and determine strategies to protect them from disruption by nighttime light.

As we learn more about the interaction between light and the brain, technology promises new solutions as well. 'Smart' homes and 'smart' lighting fixtures use precise LEDs to adjust the wavelength of light depending on the time of day. Apps for smartphones, tablets and computers are available to automatically redshift the color of the screen in the evening to a wavelength less likely to activate ipRGCs. New street light designs are being introduced to focus the light toward the street and avoid upward light leakage. And heavy black out curtains impermeable to light are being adopted for bedroom use. The average person can employ many of these strategies themselves to minimize artificial light at night exposure. Specialized populations, however, may require more sophisticated solutions. For example, night shift workers require light to perform their job duties, but there is currently no acceptable solution to protect their circadian cycle without sacrificing light needed for alertness and performance. Similarly, hospital inpatients are exposed to light at night because it is a 24/7 working environment and nurses need to care for the patients at all hours. In this situation, blue light-blocking glasses or sleep masks might be considered to reduce disruptive light exposure in this vulnerable population. Future studies should determine the minimum light intensity and spectral characteristics required to elicit depressed mood in humans and then seek solutions to optimize indoor and outdoor lighting to minimize human circadian disruption. In some cases, pairing avoidance of light at night with increased exposure to relatively bright light during the day may be needed to ward off affective dysregulation. Finally, the development of additional animal models of circadian disruption and depression is also needed to discover mechanisms underlying this relationship. ${ }^{118}$

\section{CONFLICT OF INTEREST}

The authors declare no conflict of interest.

\section{ACKNOWLEDGMENTS}

Preparation of this review was supported in part by NSF grant IOS-11-18792 and NIH grant NS092388.

\section{REFERENCES}

1 Rich C, Longcore T. Ecological Consequences of Artificial Night Lighting. Island Press: Washington, DC, 2006, 458.

2 Navara KJ, Nelson RJ. The dark side of light at night: physiological, epidemiological, and ecological consequences. J Pineal Res 2007; 43: 215-224.
3 Bedrosian TA, Nelson RJ. Influence of the modern light environment on mood. Mol Psychiatry 2013; 18: 751-757.

4 Blask DE, Brainard GC, Dauchy RT, Hanifin JP, Davidson LK, Krause JA et al. Melatonin-depleted blood from premenopausal women exposed to light at night stimulates growth of human breast cancer xenografts in nude rats. Cancer Res 2005; 65: 11174-11184.

5 Fonken LK, Workman JL, Walton JC, Weil ZM, Morris JS, Haim A et al. Light at night increases body mass by shifting the time of food intake. Proc Natl Acad Sci USA 2010; 107: 18664-18669.

6 Kloog I, Haim A, Stevens RG, Barchana M, Portnov BA. Light at night codistributes with incident breast but not lung cancer in the female population of Israel. Chronobiol Int 2008; 25: 65-81.

7 Wyse CA, Selman C, Page MM, Coogan AN, Hazlerigg DG. Circadian desynchrony and metabolic dysfunction; did light pollution make us fat? Med Hypotheses 2011; 77: 1139-1144.

8 Gaston KJ, Bennie J, Davies TW, Hopkins J. The ecological impacts of nighttime light pollution: a mechanistic appraisal. Biol Rev Camb Philos Soc 2013; 88: 912-927.

9 Bunning E, Moser I. Interference of moonlight with the photoperiodic measurement of time by plants, and their adaptive reaction. Proc Natl Acad Sci USA 1969; 62: 1018-1022.

10 Falchi F, Cinzano P, Duriscoe D, Kyba CC, Elvidge CD, Baugh $\mathrm{K}$ et al. The new world atlas of artificial night sky brightness. Sci Adv 2016; 2: e1600377.

11 Rajaratnam SM, Arendt J. Health in a 24- h society. Lancet 2001; 358: 999-1005.

12 Wood B, Rea MS, Plitnick B, Figueiro MG. Light level and duration of exposure determine the impact of self-luminous tablets on melatonin suppression. Appl Ergon 2013; 44: 237-240.

13 National Sleep Foundation. 2014 Sleep in America Poll. National Sleep Foundation: Arlington, VA, 2014.

14 National Sleep Foundation. Women and Sleep. National Sleep Foundation: Arlington, VA, 2007.

$15 \mathrm{Oh} \mathrm{JH}$, Yoo H, Park HK, Do YR. Analysis of circadian properties and healthy levels of blue light from smartphones at night. Sci Rep 2015; 5: 11325.

16 Fanfulla F, Ceriana P, D'Artavilla Lupo N, Trentin R, Frigerio F, Nava S. Sleep disturbances in patients admitted to a step-down unit after ICU discharge: the role of mechanical ventilation. Sleep 2011; 34: 355-362.

17 van der Lely S, Frey S, Garbazza C, Wirz-Justice A, Jenni OG, Steiner R et al. Blue blocker glasses as a countermeasure for alerting effects of evening lightemitting diode screen exposure in male teenagers. J Adolesc Health 2015; 56: 113-119.

18 American Psychiatric Association. Diagnostic and Statistical Manual of Mental Disorders. 5th edn, American Psychiatric Publishing: Arlington, VA, USA, 2013.

19 Lambert KG, Nelson RJ, Jovanovic T, Cerda M. Brains in the city: Neurobiological effects of urbanization. Neurosci Biobehav Rev 2015; 58: 107-122.

20 Simon GE, VonKorff M. Reevaluation of secular trends in depression rates. Am J Epidemiol 1992; 135: 1411-1422.

21 Fu TS, Lee CS, Gunnell D, Lee WC, Cheng AT. Changing trends in the prevalence of common mental disorders in Taiwan: a 20-year repeated crosssectional survey. Lancet 2013; 381: 235-241.

22 Compton WM, Conway KP, Stinson FS, Grant BF. Changes in the prevalence of major depression and comorbid substance use disorders in the United States between 1991-1992 and 2001-2002. Am J Psychiatry 2006; 163: 2141-2147.

23 Berson DM, Dunn FA, Takao M. Phototransduction by retinal ganglion cells that set the circadian clock. Science 2002; 295: 1070-1073.

24 Foster RG, Provencio I, Hudson D, Fiske S, De Grip W, Menaker M. Circadian photoreception in the retinally degenerate mouse (rd/rd). J Comp Physiol A 1991; 169: 39-50.

25 Lucas RJ, Freedman MS, Munoz M, Garcia-Fernandez JM, Foster RG. Regulation of the mammalian pineal by non-rod, non-cone, ocular photoreceptors. Science 1999; 284: 505-507.

26 Ruby NF, Brennan TJ, Xie X, Cao V, Franken P, Heller HC et al. Role of melanopsin in circadian responses to light. Science 2002; 298: 2211-2213.

27 Panda S, Sato TK, Castrucci AM, Rollag MD, DeGrip WJ, Hogenesch JB et al. Melanopsin (Opn4) requirement for normal light-induced circadian phase shifting. Science 2002; 298: 2213-2216.

28 Brainard GC, Hanifin JP, Greeson JM, Byrne B, Glickman G, Gerner E et al. Action spectrum for melatonin regulation in humans: evidence for a novel circadian photoreceptor. J Neurosci 2001; 21: 6405-6412.

29 van Bommel W. Incandescent replacement lamps and health. Light Eng 2011; 19: 8-14.

30 Hattar S, Kumar M, Park A, Tong P, Tung J, Yau KW et al. Central projections of melanopsin-expressing retinal ganglion cells in the mouse. J Comp Neurol 2006; 497: 326-349.

$31 \mathrm{Ko} \mathrm{CH}$, Takahashi JS. Molecular components of the mammalian circadian clock. Hum Mol Genet 2006; 15 Spec No 2: R271-R277. 
32 Partch $\mathrm{CL}$, Green $\mathrm{CB}$, Takahashi JS. Molecular architecture of the mammalian circadian clock. Trends Cell Biol 2014; 24: 90-99.

33 Yamazaki S, Numano R, Abe M, Hida A, Takahashi R, Ueda M et al. Resetting central and peripheral circadian oscillators in transgenic rats. Science 2000; 288: 682-685.

34 Aschoff J. Circadian Rhythms in Man. Science 1965; 148: 1427-1432.

35 Albrecht U, Sun ZS, Eichele G, Lee CC. A differential response of two putative mammalian circadian regulators, mper1 and mper2, to light. Cell 1997; 91: 1055-1064.

36 Shearman LP, Zylka MJ, Weaver DR, Kolakowski LF Jr., Reppert SM. Two period homologs: circadian expression and photic regulation in the suprachiasmatic nuclei. Neuron 1997; 19: 1261-1269.

37 Shigeyoshi Y, Taguchi K, Yamamoto S, Takekida S, Yan L, Tei H et al. Lightinduced resetting of a mammalian circadian clock is associated with rapid induction of the mPer1 transcript. Cell 1997; 91: 1043-1053.

38 Chang AM, Aeschbach D, Duffy JF, Czeisler CA. Evening use of light-emitting eReaders negatively affects sleep, circadian timing, and next-morning alertness. Proc Natl Acad Sci USA 2015; 112: 1232-1237.

39 Brown SA, Zumbrunn G, Fleury-Olela F, Preitner N, Schibler U. Rhythms of mammalian body temperature can sustain peripheral circadian clocks. Curr Biol 2002; 12: 1574-1583.

40 Damiola F, Le Minh N, Preitner N, Kornmann B, Fleury-Olela F, Schibler U. Restricted feeding uncouples circadian oscillators in peripheral tissues from the central pacemaker in the suprachiasmatic nucleus. Genes Dev 2000; 14: 2950-2961.

41 Hardeland R, Madrid JA, Tan DX, Reiter RJ. Melatonin, the circadian multioscillator system and health: the need for detailed analyses of peripheral melatonin signaling. J Pineal Res 2012; 52: 139-166.

42 Brainard GC, Lewy AJ, Menaker M, Fredrickson RH, Miller LS, Weleber RG et al. Dose-response relationship between light irradiance and the suppression of plasma melatonin in human volunteers. Brain Res 1988; 454: 212-218.

43 Son GH, Chung S, Kim K. The adrenal peripheral clock: glucocorticoid and the circadian timing system. Front Neuroendocrinol 2011; 32: 451-465.

44 Wolkowitz OM, Burke H, Epel ES, Reus VI. Glucocorticoids. Mood, memory, and mechanisms. Ann N Y Acad Sci 2009; 1179: 19-40.

45 Dijk DJ, Duffy JF, Silva EJ, Shanahan TL, Boivin DB, Czeisler CA. Amplitude reduction and phase shifts of melatonin, cortisol and other circadian rhythms after a gradual advance of sleep and light exposure in humans. PLoS One 2012; 7: e30037.

46 LeGates TA, Fernandez DC, Hattar S. Light as a central modulator of circadian rhythms, sleep and affect. Nat Rev Neurosci 2014; 15: 443-454.

47 LeGates TA, Altimus CM, Wang H, Lee HK, Yang S, Zhao H et al. Aberrant light directly impairs mood and learning through melanopsin-expressing neurons. Nature 2012; 491: 594-598.

48 Harvey AG. Sleep and circadian functioning: critical mechanisms in the mood disorders? Annu Rev Clin Psychol 2011; 7: 297-319.

49 Gandhi AV, Mosser EA, Oikonomou G, Prober DA. Melatonin is required for the circadian regulation of sleep. Neuron 2015; 85: 1193-1199.

50 Zhdanova IV, Geiger DA, Schwagerl AL, Leclair OU, Killiany R, Taylor JA et al. Melatonin promotes sleep in three species of diurnal nonhuman primates. Physiol Behav 2002; 75: 523-529.

51 Zhdanova IV, Wang SY, Leclair OU, Danilova NP. Melatonin promotes sleep-like state in zebrafish. Brain Res 2001; 903: 263-268.

52 Cho JR, Joo EY, Koo DL, Hong SB. Let there be no light: the effect of bedside light on sleep quality and background electroencephalographic rhythms. Sleep Med 2013; 14: 1422-1425.

53 Marshall L, Helgadottir $\mathrm{H}$, Molle M, Born J. Boosting slow oscillations during sleep potentiates memory. Nature 2006; 444: 610-613.

54 Nishida M, Pearsall J, Buckner RL, Walker MP. REM sleep, prefrontal theta, and the consolidation of human emotional memory. Cereb Cortex 2009; 19: 1158-1166.

55 Ohayon MM, Milesi C. Artificial outdoor nighttime lights associate with altered sleep behavior in the American general population. Sleep 2016; 39: 1311-1320.

56 Koo Y, Choi J, Jung K. Sleep Disturbances and their Relationship with Excessive Exposure to Light at Night: the Korean Genome and Epidemiology Study. Sleep Medicine 2016; 14: e29-e30.

57 Palmer CA, Alfano CA. Sleep and emotion regulation: an organizing, integrative review. Sleep Med Rev 2016.

58 Borniger JC, Weil ZM, Zhang N, Nelson RJ. Dim light at night does not disrupt timing or quality of sleep in mice. Chronobiol Int 2013; 30: 1016-1023.

59 Fonken LK, Nelson RJ. Dim light at night increases depressive-like responses in male $\mathrm{C} 3 \mathrm{H} / \mathrm{HeNH}$ sd mice. Behav Brain Res 2013; 243: 74-78.

60 Bedrosian TA, Galan A, Vaughn CA, Weil ZM, Nelson RJ. Light at night alters daily patterns of cortisol and clock proteins in female Siberian hamsters. J Neuroendocrinol 2013; 25: 590-596.
61 Fonken LK, Aubrecht TG, Melendez-Fernandez OH, Weil ZM, Nelson RJ. Dim light at night disrupts molecular circadian rhythms and increases body weight. J Biol Rhythms 2013; 28: 262-271.

62 Shuboni D, Yan L. Nighttime dim light exposure alters the responses of the circadian system. Neuroscience 2010; 170: 1172-1178.

63 Roybal K, Theobold D, Graham A, DiNieri JA, Russo SJ, Krishnan V et al. Mania-like behavior induced by disruption of CLOCK. Proc Natl Acad Sci USA 2007; 104: 6406-6411.

64 Etain B, Jamain S, Milhiet V, Lajnef M, Boudebesse C, Dumaine A et al. Association between circadian genes, bipolar disorders and chronotypes. Chronobiol Int 2014; 31: 807-814.

65 Etain B, Milhiet V, Bellivier F, Leboyer M. Genetics of circadian rhythms and mood spectrum disorders. Eur Neuropsychopharmacol 2011; 21: S676-S682.

66 Milhiet V, Etain B, Boudebesse C, Bellivier F. Circadian biomarkers, circadian genes and bipolar disorders. J Physiol Paris 2011; 105: 183-189.

67 Yamaguchi Y, Suzuki T, Mizoro Y, Kori H, Okada K, Chen Y et al. Mice genetically deficient in vasopressin $\mathrm{V} 1 \mathrm{a}$ and $\mathrm{V} 1 \mathrm{~b}$ receptors are resistant to jet lag. Science 2013; 342: 85-90.

68 Gibson EM, Wang C, Tjho S, Khattar N, Kriegsfeld LJ. Experimental 'jet lag' inhibits adult neurogenesis and produces long-term cognitive deficits in female hamsters. PLoS One 2010; 5: e15267.

69 Kott J, Leach G, Yan L. Direction-dependent effects of chronic "jet-lag" on hippocampal neurogenesis. Neurosci Lett 2012; 515: 177-180.

70 Cho K. Chronic 'jet lag' produces temporal lobe atrophy and spatial cognitive deficits. Nat Neurosci 2001; 4: 567-568.

71 Young DM. Psychiatric morbidity in travelers to Honolulu, Hawaii. Compr Psychiatry 1995; 36: 224-228.

72 Rosen LN, Targum SD, Terman M, Bryant MJ, Hoffman H, Kasper SF et al. Prevalence of seasonal affective disorder at four latitudes. Psychiatry Res 1990; 31: 131-144.

73 Glickman G, Byrne B, Pineda C, Hauck WW, Brainard GC. Light therapy for seasonal affective disorder with blue narrow-band light-emitting diodes (LEDs). Biol Psychiatry 2006; 59: 502-507.

74 Bjorksten KS, Bjerregaard P, Kripke DF. Suicides in the midnight sun--a study of seasonality in suicides in West Greenland. Psychiatry Res 2005; 133: 205-213.

75 Bjorksten KS, Kripke DF, Bjerregaard P. Accentuation of suicides but not homicides with rising latitudes of Greenland in the sunny months. BMC Psychiatry 2009; 9: 20

76 Bremner JD, Narayan M, Anderson ER, Staib LH, Miller HL, Charney DS. Hippocampal volume reduction in major depression. Am J Psychiatry 2000; 157: 115-118.

77 Sheline $\mathrm{Yl}$, Gado $\mathrm{MH}$, Kraemer HC. Untreated depression and hippocampal volume loss. Am J Psychiatry 2003; 160: 1516-1518.

78 Sheline YI, Sanghavi M, Mintun MA, Gado MH. Depression duration but not age predicts hippocampal volume loss in medically healthy women with recurrent major depression. J Neurosci 1999; 19: 5034-5043.

79 Sen S, Duman R, Sanacora G. Serum brain-derived neurotrophic factor, depression, and antidepressant medications: meta-analyses and implications. Biol Psychiatry 2008; 64: 527-532.

80 Player MJ, Taylor JL, Weickert CS, Alonzo A, Sachdev P, Martin D et al. Neuroplasticity in depressed individuals compared with healthy controls. Neuropsychopharmacology 2013; 38: 2101-2108.

81 Pittenger C, Duman RS. Stress, depression, and neuroplasticity: a convergence of mechanisms. Neuropsychopharmacology 2008; 33: 88-109.

82 Fujioka A, Fujioka T, Tsuruta R, Izumi T, Kasaoka S, Maekawa T. Effects of a constant light environment on hippocampal neurogenesis and memory in mice. Neurosci Lett 2011; 488: 41-44.

83 Karatsoreos IN, Bhagat S, Bloss EB, Morrison JH, McEwen BS. Disruption of circadian clocks has ramifications for metabolism, brain, and behavior. Proc Natl Acad Sci USA 2011; 108: 1657-1662.

84 Ma WP, Cao J, Tian M, Cui MH, Han HL, Yang YX et al. Exposure to chronic constant light impairs spatial memory and influences long-term depression in rats. Neurosci Res 2007; 59: 224-230.

85 Fonken LK, Kitsmiller E, Smale L, Nelson RJ. Dim nighttime light impairs cognition and provokes depressive-like responses in a diurnal rodent. J Biol Rhythms 2012; 27: 319-327.

86 Bedrosian TA, Fonken LK, Walton JC, Haim A, Nelson RJ. Dim light at night provokes depression-like behaviors and reduces CA1 dendritic spine density in female hamsters. Psychoneuroendocrinology 2011; 36: 1062-1069.

87 Bedrosian TA, Vaughn CA, Galan A, Daye G, Weil ZM, Nelson RJ. Nocturnal light exposure impairs affective responses in a wavelength-dependent manner. J Neurosci 2013; 33: 13081-13087.

88 Wirz-Justice A. Circadian rhythms in mammalian neurotransmitter receptors. Prog Neurobiol 1987; 29: 219-259. 
89 Weiner N, Clement HW, Gemsa D, Wesemann W. Circadian and seasonal rhythms of 5-HT receptor subtypes, membrane anisotropy and 5-HT release in hippocampus and cortex of the rat. Neurochem Int 1992; 21: 7-14.

90 Malek ZS, Dardente H, Pevet P, Raison S. Tissue-specific expression of tryptophan hydroxylase mRNAs in the rat midbrain: anatomical evidence and daily profiles. Eur J Neurosci 2005; 22: 895-901.

91 Khaldy H, Leon J, Escames G, Bikjdaouene L, Garcia JJ, Acuna-Castroviejo D. Circadian rhythms of dopamine and dihydroxyphenyl acetic acid in the mouse striatum: effects of pinealectomy and of melatonin treatment. Neuroendocrinology 2002; 75: 201-208.

92 Barassin S, Raison S, Saboureau M, Bienvenu C, Maitre M, Malan A et al. Circadian tryptophan hydroxylase levels and serotonin release in the suprachiasmatic nucleus of the rat. Eur J Neurosci 2002; 15: 833-840.

93 Hampp G, Ripperger JA, Houben T, Schmutz I, Blex C, Perreau-Lenz S et al. Regulation of monoamine oxidase $A$ by circadian-clock components implies clock influence on mood. Curr Biol 2008; 18: 678-683.

94 Ikeno T, Yan L. Chronic light exposure in the middle of the night disturbs the circadian system and emotional regulation. J Biol Rhythms 2016; 31: 352-364.

95 Castaneda TR, de Prado BM, Prieto D, Mora F. Circadian rhythms of dopamine, glutamate and GABA in the striatum and nucleus accumbens of the awake rat: modulation by light. J Pineal Res 2004; 36: 177-185.

96 Shieh KR, Chu YS, Pan JT. Circadian change of dopaminergic neuron activity: effects of constant light and melatonin. Neuroreport 1997; 8: 2283-2287.

97 Dulcis D, Jamshidi P, Leutgeb S, Spitzer NC. Neurotransmitter switching in the adult brain regulates behavior. Science 2013; 340: 449-453.

98 Matsumura T, Nakagawa H, Suzuki K, Ninomiya C, Ishiwata T. Influence of circadian disruption on neurotransmitter levels, physiological indexes, and behaviour in rats. Chronobiol Int 2015; 32: 1449-1457.

99 Quinn GE, Shin CH, Maguire MG, Stone RA. Myopia and ambient lighting at night. Nature 1999; 399: 113-114.

100 Vollmer C, Michel U, Randler C. Outdoor light at night (LAN) is correlated with eveningness in adolescents. Chronobiol Int 2012; 29: 502-508.

101 Higuchi S, Nagafuchi Y, Lee SI, Harada T. Influence of light at night on melatonin suppression in children. J Clin Endocrinol Metab 2014; 99: 3298-3303.

102 Borniger JC, McHenry ZD, Abi Salloum BA, Nelson RJ. Exposure to dim light at night during early development increases adult anxiety-like responses. Physiol Behav 2014; 133: 99-106.

103 Martynhak BJ, Correia D, Morais LH, Araujo P, Andersen ML, Lima MM et al. Neonatal exposure to constant light prevents anhedonia-like behavior induced by constant light exposure in adulthood. Behav Brain Res 2011; 222: $10-14$

104 Scott AJ, Monk TH, Brink LL. Shiftwork as a risk factor for depression: a pilot study. Int J Occup Environ Health 1997; 3: S2-S9.

105 Healy D, Minors DS, Waterhouse JM. Shiftwork, helplessness and depression. J Affect Disord 1993; 29: 17-25.
106 Czeisler CA, Johnson MP, Duffy JF, Brown EN, Ronda JM, Kronauer RE. Exposure to bright light and darkness to treat physiologic maladaptation to night work. N Engl J Med 1990; 322: 1253-1259.

107 Iwata N, Ichii S, Egashira K. Effects of bright artificial light on subjective mood of shift work nurses. Ind Health 1997; 35: 41-47.

108 Lewy AJ, Nurnberger JI Jr., Wehr TA, Pack D, Becker LE, Powell RL et al. Supersensitivity to light: possible trait marker for manic-depressive illness. Am J Psychiatry 1985; 142: 725-727.

109 Egeland JA, Hostetter AM. Amish Study, I: affective disorders among the Amish, 1976-1980. Am J Psychiatry 1983; 140: 56-61.

110 Pandi-Perumal SR, Zisapel N, Srinivasan V, Cardinali DP. Melatonin and sleep in aging population. Exp Gerontol 2005; 40: 911-925.

111 Obayashi K, Saeki K, Kurumatani N. Association between light exposure at night and insomnia in the general elderly population: the HEIJO-KYO cohort. Chronobiol Int 2014; 31: 976-982.

112 Obayashi K, Saeki K, Iwamoto J, Ikada Y, Kurumatani N. Exposure to light at night and risk of depression in the elderly. J Affect Disord 2013; 151: 331-336.

113 Mishima K, Okawa M, Hishikawa Y, Hozumi S, Hori H, Takahashi K. Morning bright light therapy for sleep and behavior disorders in elderly patients with dementia. Acta Psychiatr Scand 1994; 89: 1-7.

114 Harb F, Hidalgo MP, Martau B. Lack of exposure to natural light in the workspace is associated with physiological, sleep and depressive symptoms. Chronobiol Int 2015; 32: 368-375.

115 Davis S, Mirick DK, Stevens RG. Night shift work, light at night, and risk of breast cancer. J Natl Cancer Inst 2001; 93: 1557-1562.

116 Stevens RG. Light-at-night, circadian disruption and breast cancer: assessment of existing evidence. Int J Epidemiol 2009; 38: 963-970.

117 Human and Environmental Effects of Light Emitting Diode (LED) Community Lighting. American Medical Association, Report of the Council on Science and Public Health. 2016, pp 1-8; http://darksky.org/wp-content/uploads/bsk-pdfmanager/AMA_Report_2016_60.pdf Community Lighting.

118 Kronfeld-Schor N, Einat H. Circadian rhythms and depression: human psychopathology and animal models. Neuropharmacology 2012; 62: 101-114.

119 Meyer TJ, Eveloff SE, Bauer MS, Schwartz WA, Hill NS, Millman RP. Adverse environmental conditions in the respiratory and medical ICU settings. Chest 1994; 105: 1211-1216.

This work is licensed under a Creative Commons AttributionNonCommercial-NoDerivs 4.0 International License. The images or other third party material in this article are included in the article's Creative Commons license, unless indicated otherwise in the credit line; if the material is not included under the Creative Commons license, users will need to obtain permission from the license holder to reproduce the material. To view a copy of this license, visit http:// creativecommons.org/licenses/by-nc-nd/4.0/

(c) The Author(s) 2017 